\title{
Sistema Andaluz de Museos y registro de Museos de Andalucía
}

\author{
Montserrat Barragán Jané \\ Conservadora de Museos
}

\begin{abstract}
Resumen
Desde la entrada en vigor de la legislación andaluza que regula y define el Sistema Andaluz de Museos y el Registro de Museos de Andalucía, la administración autonómica ha ido definiendo el contenido de estos dos instrumentos fundamentales en la articulación del panorama museístico de Andalucía. El artículo incide en la puesta en funcionamiento de estos dos instrumentos, que permiten a la Consejería de Cultura ejercer no sólo una labor de aprobación e inspección de estas instituciones sino también habilitar una serie de medidas de fomento para las mismas.
\end{abstract}

\section{Palabras clave}

Sistema Andaluz de Museos / Registro de Museos de Andalucía / Comisión Andaluza de Museos / Dirección General de Instituciones del Patrimonio Histórico / Legislación / Museos locales / Andalucía

\section{Sistema Andaluz de Museos}

Andalucía fue la primera Comunidad Autónoma que abordó la planificación y coordinación de sus museos, a través de la Ley 2/1984, de 9 de enero, de Museos de Andalucía, y establecía en ella que el Sistema Andaluz de Museos se constituía como una red de museos andaluces y como una unidad de gestión al servicio de la comunidad' en la que están incluidos, además de la Consejería de Cultura y la Comisión Andaluza de Museos, todos los museos existentes o que se creen en el futuro en Andalucía, sea cual sea su titularidad, que deban considerarse integrados en este sistema en virtud de lo dispuesto en el art. 10 de la Ley de Museos².
Este art. 10 de la mencionada Ley establece, por su parte, que todos los museos de titularidad pública quedan integrados en el SAM, así como los museos de titularidad privada que reciban una aportación económica de la Administración pública que supere la mitad de su presupuesto o beneficios fiscales de más del 10\% del mismo. El resto de los museos podrá integrarse en el SAM a través de los oportunos convenios con la Consejería de Cultura. La práctica administrativa, encaminada a elaborar un listado lo más completo posible de todas las instituciones museísticas de la Comunidad, ha incluido en el SAM a todos los museos privados de Andalucía sin necesidad de convennio alguno.

Por lo que respecta a los museos gestionados por la Junta de Andalucía, la Resolución de 27 de mayo de 1994, de la Dirección General de Bienes Culturales por la que se da publicidad a los Convenios entre el Ministerio de Cultura y la Consejería de Cultura y Medio Ambiente, sobre Gestión de Archivos y Museos de titularidad estatal [...] establece en su artículo 5.3 que los archivos y museos de titularidad estatal se integran en los Sistemas Españoles correspondientes. Lo anterior no es obstáculo para que los museos objeto de este Convenio se incorporen al Sistema Andaluz de Museos, con el fin de conseguir la debida coordinación técnica y administrativa de los mismos con los de titularidad autonómica, así como una eficaz sistematización de todos los servicios museológicos.

De forma expresa, la Consejería de Cultura aún no ha incorporado los Museos de titularidad estatal en el SAM aunque, como hemos visto, en el art. 10 de la Ley de Museos se establece que quedan integrados estos museos.

Este empeño por regularizar el panorama museístico de Andalucía se realizó en un contexto muy diferente del actual en lo que respecta a los museos de titularidad municipal o privada. De hecho, alguno de los problemas que ha encontrado la Administración Autonómica en la concreción del Sistema derivan del cambio espectacular que el panorama museístico andaluz ha experimentado en los últimos años. 
En primer lugar, lo más llamativo ha sido la proliferación de instituciones a las que se les aplica el nombre de museo. Tanto es así que puede estimarse que en el momento en el que se reguló el Sistema Andaluz de Museos, el número de estas instituciones no alcanzaría el 20\% del numero actual que sobrepasa los 300 museos y colecciones.

Hoy en día resulta raro encontrar un municipio de cierta entidad que no cuente con museo o que no tenga previsto la realización de uno dentro de algún proyecto de desarrollo local aprovechando alguna peculiaridad de la zona: riqueza arqueológica, artista o personaje local de relevancia, artesanía o proceso industrial propia de la localidad, etc. Tampoco es extraño encontrar referencias de particulares que, habiendo reunido una serie de objeto de la naturaleza más diversa, anuncian la existencia de su colección y habilitan algún espacio para que pueda ser visitada por el público.

Esta efervescencia en la creación de museos origina el primer problema que encontramos a la hora de definir numéricamente las dimensiones del Sistema Andaluz de Museos. El número de museos que integran el SAM es muy alto (superan ligeramente los 300), pero la información de que se dispone sobre ellos es muy dispar ya que hay que tener en cuenta que muchos de los promotores y titulares de estas instituciones no se ponen en contacto con la Consejería de Cultura para notificar la situación de los mismos; es decir, si están en proceso de creación, de reforma o cerrados temporalmente por alguna razón.

La Dirección General de Instituciones del Patrimonio Histórico viene realizando una labor de investigación casi detectivesca sobre la existencia de todo museo o colección de los que se tiene noticia y anualmente se les remite un escrito en el que se solicita que cumplimenten un simple cuestionario a fin de recabar algunos datos básicos sobre los fondos y servicios de estos museos. Ni que decir tiene que un alto porcentaje de estos museos no responden a la solicitud por lo que resulta difícil conocer la situación real y actualizada de un buen número de estas instituciones.

De esta circunstancia se desprende el segundo problema que encontramos en la concreción del SAM. A pesar de que la legislación andaluza es muy clara en cuanto a lo que debe entenderse por museo ${ }^{3}$, las instancias muni- cipales y privadas aplican este nombre a instituciones que no reúnen todos los requisitos que establece le legislación para ser considerados como tales. Algunos museos están en proyecto, otros carecen de una colección debidamente inventariada, la mayoría no cuentan con personal ni medios de mantenimiento suficiente $y$, por último, otros muchos permanecen cerrados al público.

Por este motivo, y porque la realidad nos demuestra que existe una gran disparidad entre unos centros y otros, en una futura reforma de la legislación al respecto, debería distinguirse entre los conceptos de museo y de colección, tal y como se recoge en la legislación de algunas Comunidades Autónomas como Cataluña, Castilla y León, Extremadura, Valencia o Galicia, etc. Esto permitiría distinguir estas instituciones según la medida de su complejidad en la prestación de servicios y en sus instalaciones, así como el grado de dedicación a la actividad museística entendida en el amplio sentido de la palabra, tal y como establece la definición de museos de la Ley de Museos de Andalucía. En la que además, se establece que los museos en Andalucía deben estar dotados de instalaciones, personal y medios de mantenimiento suficientes ${ }^{4}$.

De este modo, el SAM consiste en una relación completa de todos las instituciones museísticas de Andalucía sea cual sea su titularidad, características y nivel de desarrollo. En la práctica, el Sistema Andaluz de Museos está integrado por tres tipos de instituciones:

I. Centros que han promovido su inclusión en el Registro de Museos de Andalucía según lo establecido en el Reglamento de creación de museos y gestión de fondos museográficos de la Comunidad Autónoma de Andalucía.

2. Centros de los que se dispone de información directa en cuanto a sus fondos y servicios y a los que les resultará de aplicación el citado Reglamento una vez que soliciten su inclusión en el mismo.

3. Centros de los que se presupone su existencia pero de los que se carece de información sobre sus características y situación.

Incluimos una tabla con los datos actualizados de todos los museos y colecciones de Andalucía:

\section{TABLA DE LOS MUSEOS Y COLECCIONES DE ANDALUCÍA}

\begin{tabular}{llc}
\hline Museos de titularidad estatal gestionados por la Consejería de Cultura & 18 \\
\hline Museos de titularidad autonómica gestionados por la Consejería de Cultura & 6 \\
\hline Museos inscritos en el Registro de Museos de Andalucía & 39 \\
\hline Museos anotados preventivamente en el Registro de Museos de Andalucía & 16 \\
\hline TOTAL & & 79 \\
\hline & Almería & 11 \\
\cline { 2 - 3 } & Cádiz & 27 \\
\cline { 2 - 3 } Otros museos y colecciones de Andalucía & Córdoba & 29 \\
\cline { 2 - 3 } & Granada & 30 \\
\cline { 2 - 3 } & Huelva & 19 \\
\cline { 2 - 3 } & Jaén & 19 \\
\cline { 2 - 3 } & Málaga & 36 \\
\cline { 2 - 3 } & Sevilla & 58 \\
\cline { 2 - 3 } & TOTAL & 229 \\
\hline TOTAL ESTIMADO & & 308 \\
\hline
\end{tabular}


La inclusión de un museo en el RAM le concede un "certificado de calidad" otorgado por la Dirección General de Instituciones del Patrimonio Histórico

\section{Registro de museos de Andalucía}

El artículo 5.3 de la Ley 2/1984, de 9 de enero, de Museos de Andalucía establece que "la Consejería de Cultura mantendrá un registro actualizado de los museos radicados en Andalucía, cualquiera que sea su titularidad, así como de sus fondos y dotación de los servicios. En diciembre de cada año se publicarán en el Boletín Oficial de la Junta de Andalucía, la relación de los nuevos museos integrados en el Sistema Andaluz de Museos y de las bajas que se hayan producido" 5 .

El Decreto 284/1995, de 28 de noviembre, por el que se aprueba el Reglamento de creación de museos y de gestión de fondos museísticos de la Comunidad Autónoma de Andalucía, desarrolla reglamentariamente la Ley de Museos de Andalucía y establece un instrumento de control y fomento que es el Registro de Museos de Andalucía (RAM).

Dentro del RAM se distingue entre museos que están anotados preventivamente en el y museos que están inscritos. Esta diferenciación permite distinguir entre aquellos museos que están aún en fase de ejecución y han solicitado la aprobación de viabilidad del proyecto y aquellos que ya han finalizado la ejecución del proyecto. A aquellos museos que ya existían cuando entró en vigor esta normativa, la Disposición Transitoria del Reglamento mencionado les concedía un periodo de un año para tramitar su inscripción en el registro; una vez caducado este plazo, estos museos deben acomodar su petición al procedimiento establecido en el Título II del Reglamento ..., aunque debe entenderse que el trámite de anotación preventiva y de inscripción definitiva es prácticamente simultáneo ya que estos museos no están en proceso de formación sino que ya son una realidad. Por otro lado, el RAM se estructura en tres secciones:

a. Museos de titularidad autonómica

b. Museos de titularidad pública no autonómica

c. Museos de titularidad privada

La ley andaluza establece por tanto, un objetivo: el Sistema Andaluz de Museos, y un instrumento: el Regis- tro de Museos de Andalucía, por el cual además se accede a determinados beneficios y medidas de fomento. Puede entenderse que la inclusión de un museo en el RAM le concede un "certificado de calidad" otorgado por la Dirección General de Instituciones del Patrimonio Histórico que certifica que determinado museo ha cumplimentado sastifactoriamente los apartados que se establecen en el mencionado Reglamento: Programa institucional, museológico y museográfico ${ }^{6}$.

Debe entenderse el RAM como un instrumento de homologación de los museos andaluces que proporciona información sobre el grado de cumplimiento de los aspectos científicos y técnicos previstos en la legislación andaluza. Se considera, por tanto, un instrumento administrativo de gestión y difusión de los museos andaluces que informa a la administración de su situación y le permite planificar las acciones correspondientes.

Para que el Registro de Museos de Andalucía pueda cumplir con estos objetivos, se impone la inspección de estos museos en los procesos de anotación preventiva e inscripción definitiva. Esto permitiría además que estos museos planificaran sus actuaciones y subsanaran las deficiencias encontradas por la Dirección General de Instituciones del Patrimonio y por la Comisión Andaluza de Museos.

Actualmente se realizan inspecciones de los museos que han promovido expedientes de autorización de creación tanto por parte de las Delegaciones Provinciales de la Consejería de Cultura, como por parte de la Comisión Andaluza de Museos en el proceso de anotación preventiva. Si la inclusión de estos museos en el RAM les concede un "sello de calidad" a estas instituciones, la Dirección General de Instituciones del Patrimonio Histórico debería arbitrar fórmulas que posibilitaran las inspecciones periódicas. De esta forma, existiría la seguridad de que las características que permitieron incluir a estos museos en el RAM se mantienen en el tiempo. En este sentido, la legislación de Museos de algunas Comunidades Autónomas establede específicamente la necesidad de que los museos incluidos en sus correspondientes sistemas ma- 
nengan las condiciones iniciales aprobadas en su día, condenando a estos centros anquilosamiento e impidiendo su renovación museográfica.

Algunos museos inscritos y anotados en el Registro han abordado remodelaciones, a veces muy sustantivas de algunos aspectos de los proyectos aprobados en su día por la Comisión Andaluza de Museos y por la Consejería de Cultura que se refieren a las instalaciones, edificio, ampliación de colecciones, etc. Todos los museos están obligados a remitir información mediante una memoria-balance anual que deben enviar a la Consejería de Cultura ${ }^{7}$, pero no está previsto que sea necesario el "visto bueno" de la administración a los proyectos de ampliación, remodelación, etc. Dado que estas actuaciones pueden modificar o alterar total o parcialmente el proyecto al que se concedió la viabilidad, debería regularse de forma explíita la necesidad de que estos cambios sean informados positivamente por la Comisión Andaluza de Museos y posteriormente autorizados por la Dirección General de Instituciones del Patrimonio Histórico.

Aunque la documentación que deben enviar los museos que solicitan su inclusión en el Registro aparece debidamente especificada en el Art. 6 del Reglamento citado, es muy frecuente que esta documentación llegue con deficiencias a la Consejería de Cultura tanto por omisión de la misma como por no haberse entendido las características de la información que se requiere. Esta circunstancia ha sido resuelta en Cataluña mediante la elaboración de un cuestionario que homologa la toma de datos en los procesos de anotación, inscripción e inspección, y en esa misma línea está en fase de estudio un documento de similares características por parte de la Dirección General de Instituciones del Patrimonio.

Aspecto más delicado, y que debería tratarse en profundidad, es el que se refiere a las dimensiones, al menos mínimas, de los ítem que se requieren en la documentación que se solicita para tramitar la anotación en el Registro. Es decir, a los museos se les solicitan datos sobre el personal, el presupuesto, el horario, las dimensiones de las instalaciones, etc., pero la Consejería de Cultura no dispone de un baremo que establezca cuál debería ser la dimensión mínima de estos aspectos para que una institución cumpla con las funciones y la definición que la legislación andaluza establece para los museos ${ }^{8}$.

Tanto los miembros de la Comisión Andaluza de Museos como el personal técnico de la Dirección General de Instituciones del Patrimonio Histórico valoran estas cuestiones según criterios museológicos, pero un respaldo legal facilitaría la resolución de los expedientes, anularía la posible variabilidad de los criterios en la autorización de creación de museos, aseguraría una calidad mínima real del servicio público que prestan estas instituciones y no desdeciría del respaldo que la Consejería de Cultura les concede.

Cualquier persona que visite varios de los museos incluidos en el Registro puede comprobar que existe una gran diferencia en cuanto a dimensiones de las instalaciones, calidad de los fondos y dotación de personal, etc. Estas diferencias en instituciones que reciben todas por igual el nombre de museo se deben, en gran parte, a que los promotores de estas instituciones son en la mayoría de los casos, municipios de dimensiones tan variadas como lo son las partidas presupuestarias destinadas a mantenerlas. $\mathrm{Ni}$ que decir tiene que también son evidentes las diferencias entre los museos de titularidad pública y los de titularidad privada en aspectos tales como los servicios complementarios que ofrecen (librería, cafetería, etc.), la dedicación a promover actividades que atraigan el mayor número posible de visitantes y el interés porque la exposición sea lo más atractiva posible.

Otras diferencias menos evidentes radican en la infraestructura con la que están dotados estos centros, es decir, talleres de restauración, almacenes, etc., así como el equipamiento de los mismos. Más evidente resultan los medios didácticos con los que cuenta el museo, las actividades encaminadas a la difusión que estos realizan, etc. Estas diferencias podrían encontrar una plasmación reglamentaria si la legislación estableciera la distinción ya señalada entre Museo y Colección museográfica. De modo que aquellas instituciones que ofrecen una menor complejidad en sus servicios o en las que el grado de dedicación museística es menor por razones presupuestarias y de personal, pudieran ser definidas como Colecciones museográficas y no como Museo.

Por otro lado, hay promotores de la creación de algún museo que han visto denegada su solicitud por parte de la Dirección General de Instituciones del Patrimonio mediante una Resolución negativa, tras un informe negativo de la Comisión Andaluza de Museos. Aunque la legislación andaluza no establece nada expresamente en cuanto a las consecuencias de esta resolución y al plazo en el que los titulares de estos centros pueden volver a solicitar su inclusión en el Registro, se entiende en la práctica que cuando las causas que motivaron la Resolución negativa han sido subsanadas, se puede volver a iniciar el expediente de anotación preventiva. En cualquier caso, convendría que la legislación andaluza recogiera de forma expresa esta circunstancia.

Por último, el art. 10 del Reglamento de creación de museos ... regula el procedimiento y las causas de cancelación de la inscripción de los museos en el Registro, y esto es un elemento novedoso entre todas las legislaciones de museos de las distintas Comunidades Autónomas. Hasta el momento no se ha producido ninguna cancelación de inscripción de museos del Registro ni a petición de algún particular ni de oficio por parte de la Administración. Teniendo en cuenta la experiencia adquirida en estos años de aplicación de la legislación al respecto, la Administración Autonómica ha ido afinando y depurando los criterios aplicables en la inclusión de museos en el Registro; además, los proyectos de creación de museos presentados recientemente muestran un nivel muy destacado que posiblemente tenga mucho 
que ver con la propia consideración del público general sobre lo que los museos deben ser.

Para todo ello, un procedimiento regulado de inspección de los museos anotados e inscritos en el Registro facilitaría la información sobre la realidad de los mismos y la adecuación de las instalaciones con lo expresado en los proyectos y en las memorias de ejecución, y sería un instrumento fundamental que facilita- ría la apertura de procedimientos de cancelación de inscripción si se tuviera constancia de que concurren algunas de las causas previstas en dicho art. 109.

A continuación ofrecemos el listado de los museos que integran el Registro de Museos de Andalucía, así como una clasificación según las temáticas y la titularidad de los mismos repartidos en las distintas provincias andaluzas:

\section{MUSEOS INSCRITOS EN EL REGISTRO DE MUSEOS DE ANDALUCÍA: 39}

1997-Museo Histórico Municipal de San Fernando (Cádiz)

1997-Parque de las Ciencias de Granada

1997-Museo Histórico Municipal de Cañete de las Torres (Córdoba)

1997-Museo Histórico Municipal de Priego (Córdoba)

1997-Museo Minero de Riotinto (Huelva)

1997-Museo del Grabado Español Contemporáneo de Marbella (Málaga)

1997-Museo de Prehistoria y Paleontología de Orce (Granada)

1997-Museo Histórico Municipal de Montilla (Córdoba)

1997-Museo Histórico Local de Puente Genil (Córdoba)

1997-Museo Municipal del Puerto de Santa Ma (Cádiz)

1997-Museo Histórico Popular del Bandolero de Ronda (Málaga)

1997-Museo Fundación Rafael Alberti de El Puerto de Santa Mª (Cádiz)

1997-Museo Municipal de Antequera (Málaga)

1997-Museo de Arte Contemporáneo José Maa Moreno Galván de Puebla de Cazalla (Sevilla)

1997-Museo Histórico Municipal de Santaella (Córdoba)

1997-Museo Casa Natal y Museo de N. Alcalá-Zamora de Priego (Córdoba)

1997-Museo Municipal de Pizarra (Málaga)

1997-Museo Histórico Arqueológico de Almedinilla (Córdoba)

1997-Museo Histórico Municipal de Fuente-Tójar (Córdoba)

1997-Museo Arqueológico Municipal de Montoro (Córdoba)

1997-Museo Municipal de Palma del Río (Córdoba)

1997-Museo Municipal de Ronda (Málaga)

1997-Museo Arqueológico Municipal de Cabra (Córdoba)

1997-Museo Arqueológico de Da Mencía (Córdoba)

1997-Museo Comarcal Velezano Miguel Guirao de Vélez-Rubio (Almería)

1997-Museo Municipal de Baza (Granada)

1997-Museo de Ulía de Montemayor (Córdoba)

1997-Museo del Anís de Rute (Córdoba)

1997-Museo Julio Romero de Torres (Córdoba)

1997-Museo Cruz Herrera de la Línea de la Concepción (Cádiz)

1997-Casa Museo de Pedro Muñoz Seca de El Puerto de Santa Mª (Cádiz)

1997-Museo Torre de La Calahorra (Córdoba)

1997-Museo Arqueológico Municipal de Jerez (Cádiz)

1999-Museo Histórico de Belmez y del Territorio Minero (Córdoba)

2000-Museo Antonio Manuel Campoy de Cuevas de Almanzora (Almería)

2000-Museo Histórico Municipal de Baena (Córdoba)

2000-Museo Histórico de Écija (Sevilla)

2000-Museo Arqueológico Municipal de Obulco de Porcuna (Jaén)

2000-Centro de Arte Moderno y Contemporáneo D. Vázquez Díaz de Nerva (Huelva) 
MUSEOS ANOTADOS PREVENTIVAMENTE EN EL RMA: 16

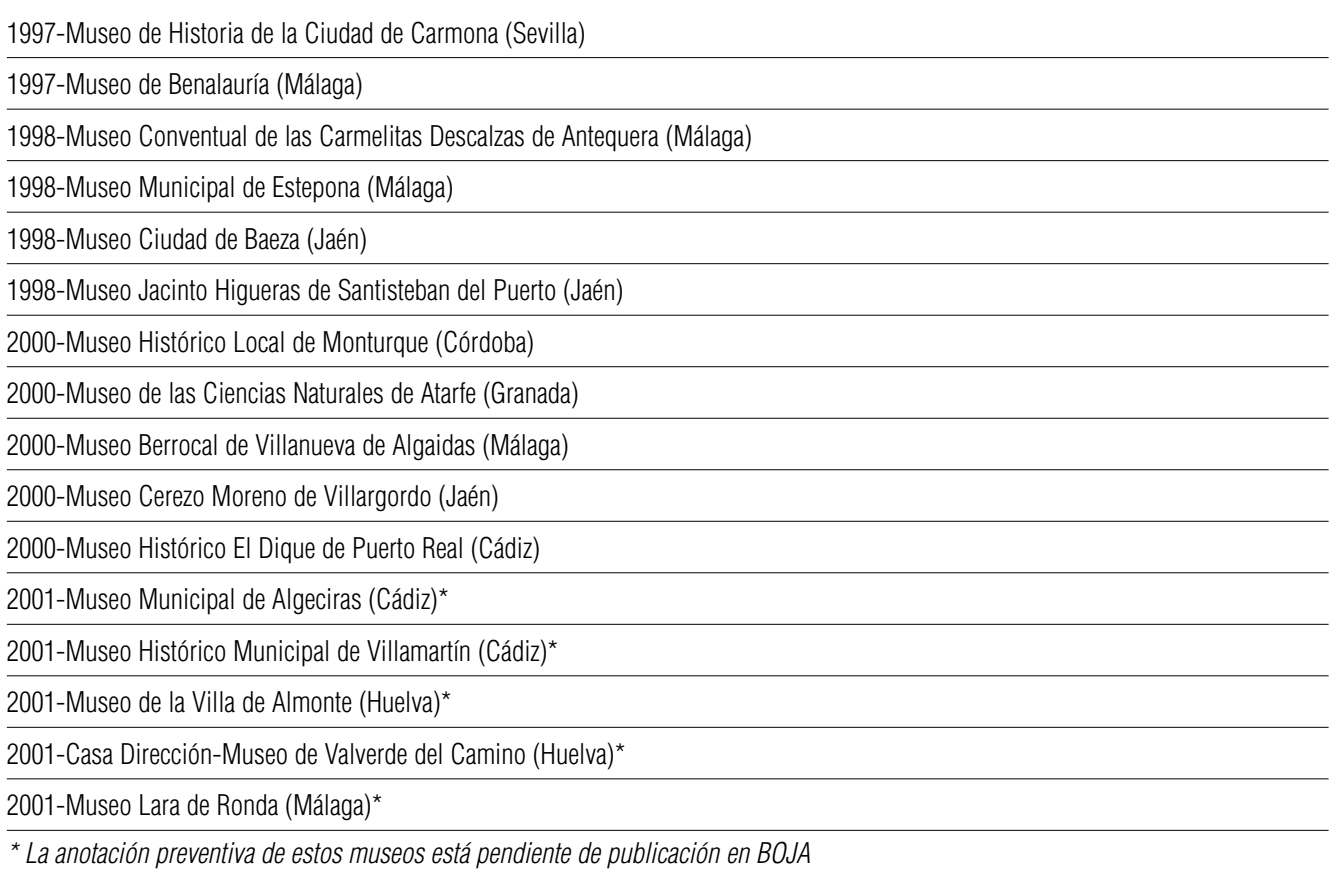

CLASIFICACIÓN DE LOS MUSEOS INSCRITOS Y ANOTADOS EN EL REGISTRO DE MUSEOS DE ANDALUCíA

\begin{tabular}{|c|c|c|c|c|c|c|c|c|c|c|c|}
\hline \multirow{2}{*}{ Provincia } & \multicolumn{2}{|c|}{ Titularidad } & \multicolumn{8}{|c|}{ Temática } & \multirow{2}{*}{ Total } \\
\hline & Pública & Privada & Arte & Historia & General & Arqueología & Etnografía & Ciencia & Casa-Museo & Especializado & \\
\hline Almería & 2 & & 1 & 1 & & & & & & & 2 \\
\hline Cádiz & 6 & 3 & 1 & 2 & 2 & 1 & & & 2 & 1 & 9 \\
\hline Córdoba & 16 & 3 & 1 & 9 & 2 & 4 & & & 1 & 2 & 19 \\
\hline Granada & 3 & 1 & & 1 & & 1 & & 2 & & & 4 \\
\hline Huelva & 3 & 1 & 1 & & & & 2 & & & 1 & 4 \\
\hline Jaén & 4 & & 2 & 1 & & 1 & & & & & 4 \\
\hline Málaga & 5 & 5 & 2 & & 3 & & 2 & & & 3 & 10 \\
\hline Sevilla & 3 & & 1 & 2 & & & & & & & 3 \\
\hline Total & 42 & 13 & 9 & 16 & 7 & 7 & 4 & 2 & 3 & 7 & 55 \\
\hline
\end{tabular}

\section{Medidas de fomento}

La pertenencia de un museo al Sistema Andaluz de Museos no implica ninguna medida de fomento especial o ventaja regulada, aunque está prevista la publicación del listado completo de los mismos en la Guía Oficial de los Museos Andaluces que edita la Consejería de Cultura.

En cambio, el Reglamento de creación de museos ... regula algunas medidas destinadas al fomento de estos centros. Concretamente, los museos inscritos y anotados preventivamente en el Registro de Museos podrán solicitar el depósito temporal de bienes del Patrimonio Histórico propiedad de la Junta de Andalucía 10. A su vez, la inscripción o anotación preventiva se considera requisito indispensable para recibir ayudas y subvenciones de la Junta de Andalucía "'.
En cualquier caso, dentro de la labor de coordinación y planificación de la organización y los servicios de los museos integrados en el Sistema Andaluz de Museos ejercida por la Consejería de Cultura, la Dirección General de IPH tiene previsto ir ampliando la colaboración no reglada con los museos inscritos o anotados preventivamente en el Registro de Museos en aspectos tales como:

- Asesoramiento técnico y científico por parte de los técnicos de la Consejería de Cultura.

- Participación en los circuitos de exposiciones temporales organizadas por la Consejería de Cultura.

- Participación en cursos específicos, reuniones y seminarios que organice la Consejería de Cultura para la mejor preparación del personal de los museos. 
En relación con este último aspecto, el panorama formativo en el campo de la museología se ha ido ampliando en los últimos años y la muestra más reciente de ello es la organización del I Máster de Museología por parte de la Consejería de Cultura en colaboración con la Universidad de Granada.

La disponibilidad de un grupo de profesionales de la museología, formados en las nuevas corrientes museológicas y con conocimientos sobre procedimientos museográficos de vanguardia, debería ser aprovechado por los promotores de museos privados y públicos para que éstos no repitan modelos decimonónicos ya caducos y sean un reflejo, por el contrario, de las nuevas posibilidades de integración con el territorio y con la población local que tienen estas instituciones.

Por otro lado, la Dirección General de Instituciones del Patrimonio Histórico ha iniciado contactos con el IAPH con el propósito de realizar una convocatoria de formación especialmente orientada a los profesionales que trabajan en estos museos y que tenga en cuenta sus circunstancias particulares así como sus necesidades formativas.

A pesar de que el nivel de los proyectos de creación de museos que se han evaluado en los últimos años ha mejorado espectacularmente, se puede detectar una cierta carencia de formación museológica en los proyectos de creación de museos que envían los promotores de los mismos, así como en las memoria-balance anuales.

Lo más habitual en el perfil del personal implicado en la gestión del patrimonio histórico local es la formación universitaria en alguna especialidad relacionada con éste, pero no la formación específica en el ámbito de la museología. Estos conocimientos, cuando existen, se han adquirido por el esfuerzo autodidacta de los interesados o por la mera experiencia tras años de gestión.

Por otro lado, dadas las limitaciones presupuestarias de las entidades que financian estos museos así como la escasez del personal (la ausencia del único técnico existente suele suponer el cierre del museo), el acceso de estos profesionales a cursos especializados de formación en el campo de la museología es prácticamente inexistente o cuanto menos harto difícil.

Por todos estos motivos, la organización por parte de la Consejería de Cultura, en colaboración con otros agentes, de encuentros anuales de museos locales que puedan servir de punto de encuentro para el intercambio de experiencias e incentiven la búsqueda de soluciones a los problemas más habituales en el desarrollo de su tarea, favorecerá la mejora del servicio público que estas instituciones prestan y en definitiva la difusión del patrimonio cultural que custodian estos centros.

\section{Art. 6 de LMA.}

2. Art. 7 de LMA.

3. Art. I de LMA: Los museos son instituciones de carácter permanente abiertas al público, orientadas al interés general de la comunidad que recogen, adquieren, ordenan, conservan, estudian y exhiben de forma científica, didáctica y estética, conjuntos de bienes muebles de valor cultural, señaladamente testimonios de la actividad del hombre y su entorno natural con fines de investigación, educación, disfrute y promoción científica y cultural.

4. Art. 2 de LMA.

5. Resolución de 25 de febrero de 1998 de la Dirección General de Instituciones del Patrimonio Histórico, por la que se hace pública la relación de los museos inscritos y anotados preventivamente (durante 1997) en el Registro de Museos de Andalucía (BOJA n 38, de 4 de abril de 1998); Resolución de 19 de enero de 1999, de la Dirección General de Instituciones del Patrimonio Histórico, por la que se hace pública la relación de los museos inscritos y anotados preventivamente en 1998 en el Registro de Museos de Andalucía (BOJA n 19, de 13 de febrero de 1999)
6. Art 6 del Reglamento de creación de museos y de gestión de fondos museísticos de la Comunidad Autónoma de Andalucía

\section{Art. I I del RCMGFM.}

8. Art. I de LMA: Los museos son instituciones de carácter permanente abiertas al público, orientadas al interés general de la comunidad que recogen, adquieren, ordenan, conservan, estudian y exhiben de forma científica, didáctica y estética, conjuntos de bienes muebles de valor cultural, señaladamente testimonios de la actividad del hombre y su entorno natural con fines de investigación, educación, disfrute y promoción científica y cultural.

9. Art. 10 del RCMGFM. Establece como causas de la cancelación de la inscripción de museos en el Registro, entre otras, la insuficiencia de medios personales y materiales para el mantenimiento de la institución con menoscabo en los objetivos y servicios, la omisión reiterada de la información debida a la Consejería de Cultura sin causa y poner en peligro la conservación y la protección de los bienes que custodian.

10. Art. 13 del RCMGFM.

I।. Art. 9.5 del RCMGFM. 